\title{
HIV-associated primary lung cancer (LC) in the era of highly active antiretroviral therapy (HAART): a multi-institutional collaboration
}

\author{
Gabriela D'Jaen', Liron Pantanowitz ${ }^{2}$, Mark Bower ${ }^{3}$, Susan Buskin ${ }^{4,5}$, Nancy Neil ${ }^{5,6}$, Erin Greco ${ }^{7}$, Timothy Cooley ${ }^{8,9}$, \\ David Henry ${ }^{10}$, Jonathan Stem ${ }^{10}$, Bruce Dezube ${ }^{11}$, Justin Stebbing ${ }^{12}$, David Aboulafia ${ }^{1,5^{*}}$
}

From $12^{\text {th }}$ International Conference on Malignancies in AIDS and Other Acquired Immunodeficiencies (ICMAOI)

Bethesda, MD, USA. 26-27 April, 2010

\section{Background}

HIV-infected individuals are at increased risk for primary LC. We wished to compare the clinico-pathologic features and treatment outcome of HIV-LC patients with HIV-negative LC patients. We also sought to compare smoking habits and immunologic features of HIV-LC patients with HIV-positive patients without LC.

\section{Methods}

A database of $75 \mathrm{HIV}$-positive patients with primary LC in the HAART era was established from an international collaboration. These cases were drawn from the archives of contributing physicians who subspecialize in HIV malignancies. Patient characteristics were compared with registry data from the Surveillance Epidemiology and End Results (SEER, $\mathrm{n}=169,091$ participants) Program and with HIV-positive individuals without LC from the Adult and Adolescent Spectrum of HIV-related Diseases (ASD, $n=36,569$ participants) Project.

\section{Results}

The median age at HIV-related LC diagnosis was 50 years compared to 68 years for SEER participants $(p<0.001)$. HIV-LC patients, like their SEER counterparts, most frequently presented with stage III ( $29 \%$ vs. $32 \%$ ) and stage IV (55\% vs. $48 \%$ ) cancers, usually with adenocarcinoma ( $41 \%$ vs. $37 \%$ ) or squamous carcinoma (32\% vs. $20 \%$ ) histologies. HIV-LC patients and ASD participants had comparable median nadir CD4+ cell

\footnotetext{
*Correspondence: hemdma@vmmc.org

'Division of Hematology/Oncology, Virginia Mason Medical Center, Seattle, WA, USA

Full list of author information is available at the end of the article
}

counts (138 vs. 160 cells $/ \mu \mathrm{L}$ ). HIV-LC patients were, however, more likely to be smokers (99\% vs. $76 \%$; $p<0.001)$ with a higher median pack-year history of cigarette consumption (41 vs. 14 pack-years; $p<0.001$ ). At LC diagnosis, their median CD4+ count was 340 cells $/ \mu \mathrm{L}$ and $86 \%$ were receiving HAART. Sixty-three (84\%) HIV-LC patients received cancer-specific treatments, but chemotherapy-associated toxicity was substantial. The median survival among HIV-LC patients and SEER participants both measured 9 months.

\section{Conclusions}

Smoking was tightly associated with the risk of HIV-LC. Most HIV patients were receiving HAART and had substantial immune reconstitution at time of LC diagnosis. They were able to receive LC treatments; their tumor types and overall survival were similar to SEER LC participants. However, HIV-LC patients were diagnosed with LC at a younger age than their HIV-negative counterparts. Future research should explore how screening and diagnostic and treatment strategies directed toward the general population may apply to HIV-positive patients at risk for LC.

\footnotetext{
Acknowledgements

This article has been published as part of Infectious Agents and Cancer Volume 5 Supplement 1, 2010: Proceedings of the $12^{\text {th }}$ International Conference on Malignancies in AIDS and Other Acquired

Immunodeficiencies (ICMAOI). The full contents of the supplement are available online at http://www.biomedcentral.com/1750-9378/5?issue=S1.

\section{Author details}

${ }^{1}$ Division of Hematology/Oncology, Virginia Mason Medical Center, Seattle, WA, USA. ${ }^{2}$ Department of Pathology, Baystate Medical Center, Tufts University School of Medicine, Springfield, MA, USA. ${ }^{3}$ Chelsea \& Westminster
} 
Hospital, London, UK. ${ }^{4}$ Public Health-Seattle and King County, HIV/AIDS Epidemiology, Seattle, WA, USA. ${ }^{5}$ University of Washington, Seattle, WA, USA. ${ }^{6}$ ICON Clinical Research, San Francisco, CA, USA. ${ }^{7}$ School of Public Health, University of California, Los Angeles, Los Angeles, CA, USA. ${ }^{8}$ Section of Hematology/Oncology, Boston Medical Center, Boston, MA, USA. ${ }^{9}$ Section of Hematology/Oncology, Boston University School of Medicine, Boston, MA, USA. ${ }^{10}$ Joan Karnell Cancer Center, Philadelphia, PA, 19107, USA.

${ }^{11}$ Department of Hematology/Oncology, Beth Israel Deaconess Medical Center, Harvard Medical School, Boston, MA, USA. ${ }^{12}$ Imperial College, Charing Cross Hospital, London, UK.

Published: 11 October 2010

\section{doi:10.1186/1750-9378-5-S1-A32}

Cite this article as: D'Jaen et al:: HIV-associated primary lung cancer (LC) in the era of highly active antiretroviral therapy (HAART): a multiinstitutional collaboration. Infectious Agents and Cancer 2010 5(Suppl 1):A32.

\section{Submit your next manuscript to BioMed Central} and take full advantage of:

- Convenient online submission

- Thorough peer review

- No space constraints or color figure charges

- Immediate publication on acceptance

- Inclusion in PubMed, CAS, Scopus and Google Scholar

- Research which is freely available for redistribution

Submit your manuscript at www.biomedcentral.com/submit 